\title{
Biocompatibility of n-butyl-2-cyanoacrylate (Histoacryl) in cervical structures of rats: prospective in vivo study
}

\author{
Yong Joon Suh ${ }^{1}$, Hyeong Won Yu², Su-Jln Kim³, Ji-Young Choe ${ }^{4}$, Hyo Jin Park ${ }^{5}$, June Young Choi², \\ Kyu Eun Lee ${ }^{3}$ \\ ${ }^{1}$ Department of Surgery, Hallym University Sacred Heart Hospital, Hallym University College of Medicine, Anyang, Korea \\ 2Department of Surgery, Seoul National University Bundang Hospital, Seongnam, Korea \\ ${ }^{3}$ Department of Surgery, Seoul National University Hospital, Seoul National University College of Medicine, Seoul, Korea \\ ${ }^{4}$ Department of Pathology, Hallym University Sacred Heart Hospital, Hallym University College of Medicine, Anyang, Korea \\ ${ }^{5}$ Department of Pathology, Seoul National University Bundang Hospital, Seongnam, Korea
}

\begin{abstract}
Purpose: We investigated the biocompatibility of $n$-butyl-2-cyanoacrylate (NBCA) in the cervical deep tissues of rats to assess its biocompatibility.

Methods: A total of 30 Sprague-Dawley rats were injected with NBCA. After 30, 90, 180, and 360 days, cubes of tissue $11 \mathrm{~cm}$ $\times 1 \mathrm{~cm} \times 1 \mathrm{~cm}$ ) surrounding the NBCA and normal tissue from the other side of the neck were excised from each rat. The adhesion of NBCA to adjacent structures was examined histologically. Cells were counted per high-power field (HPF), and fibrosis was graded with the measurement of fibrotic thickening.

Results: All animals displayed normal behavior without any symptoms of distress throughout the study. There was no recognizable inflammatory reaction, foreign body reaction, or fibrosis in the 30 control samples. The analyses of experimental samples showed significantly decreased inflammatory cell counts over time llymphoplasma cell count decreased from 100 (range, 70-100) to 30 (range, 30-50) per HPF, P = 0.010; neutrophil count decreased from 2 (range, 2-30) to 0 (range, 0-2) per HPF, $P=0.017$ ). However, there was no significant difference in the number of multinuclear giant cells throughout the study period la decrease from 22 [range, 16-34] to 16 [range, 12-22] per HPF, P = 0.287). The level of fibrosis was Common Toxicity Criteria ver. 4.0 Grade 1 without further thickening $(P=0.600)$. However, maturation of fibrosis progressed gradually.

Conclusion: NBCA was biologically tolerable in the cervical deep tissues of rats. However, precautions are needed with respect to preventing a sustained foreign body reaction and fibrosis.

[Ann Surg Treat Res 2019;96(4):162-168]
\end{abstract}

Key Words: Biocompatible materials, Cyanoacrylate, Chyle, Neck dissection

\section{INTRODUCTION}

The incidence of injury to the thoracic duct during neck dissection is as high as $4 \%[1,2]$. This complication can present significant management challenges. The current management strategy for the treatment of chyle leakage varies depending on the clinician's experience and interpretation of the medical literature [3]. Complications include fluid and electrolyte disturbances, protein loss, skin necrosis, fistula, and carotid blowout [1]. Currently, n-butyl-2-cyanoacrylate (NBCA), a solution that can be used to prevent chyle leakage, meets all requirements described in ISO (International Organization for
Received August 7, 2018, Revised October 7, 2018,

Accepted November 6, 2018

Corresponding Author: June Young Choi

Department of Surgery, Seoul National University Bundang Hospital, 82

Gumi-ro 173 Beon-gil, Bundang-gu, Seongnam 13620, Korea

Tel: +82-31-787-7107, Fax: +82-31-787-4055

E-mail: juneychoi@snubh.org

ORCID code: https://orcid.org/0000-0001-9990-607X
Copyright (C) 2019, the Korean Surgical Society

(c) Annals of Surgical Treatment and Research is an Open Access Journal. All articles are distributed under the terms of the Creative Commons Attribution NonCommercial License (http://creativecommons.org/licenses/by-nc/4.0/) which permits unrestricted non-commercial use, distribution, and reproduction in any medium, provided the original work is properly cited. 
Standardization) 10993 for internal use [4]. Promising results have recently been reported by investigators who used NBCA to treat chyle leakage [2,5-8].

NBCA is a unique substance that polymerizes within 5-6 seconds in the presence of ionic substances, such as moisture, blood, or tissue fluids and reaches the final stage of hardening in 60 seconds [7]. According to its 2013 material safety data sheet, NBCA is classified as nonhazardous and noncarcinogenic. The U.S. Food and Drug Administration (FDA) has approved NBCA for use as a topical skin adhesive. However, NBCA is not approved for subcutaneous use. The polymerized adhesive is not absorbed by any tissues. NBCA has been used extensively for various clinical applications for 40 years [9]. On September 25, 2000, the FDA approved Trufill (Cordis Neurovascular, Miami, FL, USA) as an internal embolic agent for cerebral arteriovenous malformations [10]. Trufill is a formulation comprising NBCA monomer (over 90\%, with other ingredients), ethiodized oil, and tantalum powder. Moreover, NBCA is used for various other clinical applications, including arterial embolization, variceal sclerotherapy, and fistula closure [10-13].

Before using NBCA as a treatment for chyle leakage, its biocompatibility with cervical structures should be examined. In this study, we used a rat model to evaluate the biocompatibility of NBCA in cervical deep tissues.

\section{METHODS}

\section{Animals}

Thirty 9-week-old male SPF Sprague-Dawley rats weighing $384 \pm 17 \mathrm{~g}$ (range, 350-430 g; OrientBio Inc., Seongnam, Korea) were used. The Seoul National University Bundang Hospital Institutional Animal Care and Use Committee approved this study (approval number: BA1405-152/020-01). All efforts were made to minimize the number of animals used and to ameliorate their suffering. The rats had ad libitum access to water and food, and were housed under adequate temperature $\left(23^{\circ} \mathrm{C}\right)$ and a 12 -hour light-dark cycle.

\section{Experimental design}

The neck muscles of rats are covered with loose skin [14]. The clavotrapezius is the lateralmost muscle, and the sternohyoid muscle covers the trachea. The sternomastoid muscle is located between these 2 muscles, overlying the omohyoid and cleidomastoid muscles. The space between the sternohyoid and sternomastoid muscles is easily distinguishable, and it marks the location of important anatomic structures, such as the internal jugular vein, the internal carotid artery, and the vagus nerve. We implanted $1.3 \mu \mathrm{g} / \mathrm{g}$ NBCA (Histoacryl; B. Braun, Melsungen AG, Germany) into this space and investigated its biocompatibility over a 1-year study period. For implantation, all rats were anesthetized with $2 \%$ isoflurane (Ifran; Hana
Pharm. Co., Seoul, Korea). The rats were then placed in the supine position. After skin preparation, each rat received implantation of NBCA, as described above, into the cervical deep tissues, and adhesion of NBCA to the adjacent structures was evaluated at 30,90, 180, and 360 days. At each time point, rats were euthanized by $\mathrm{CO}_{2}$ inhalation. Cubes of tissue $(1 \mathrm{~cm}$ $\times 1 \mathrm{~cm} \times 1 \mathrm{~cm}$ ) surrounding the NBCA and normal tissue from the other side of the neck were excised from each rat, fixed in $10 \%$ neutral buffered formalin solution, and embedded in paraffin. Sections $4 \mu \mathrm{m}$ thick were cut from each paraffin block and fixed on a microscope slide. The paraffin was removed by Roti-Histol, and the samples were rehydrated in isopropanol, graded ethanol $(96 \%, 80 \%, 70 \%$, and $50 \%$ in succession), and distilled water.

\section{Histologic assessment}

Samples were stained with hematoxylin and eosin (H\&E). Masson's trichrome (MT) staining was also used to evaluate fibrosis. On H\&E staining, the cell nucleus is stained blue, and the cytoplasm or the extracellular matrix is stained pink in varying degrees. On MT staining, connective tissue is stained blue, the nucleus is stained purple, and the cytoplasm is stained red. Two specialized pathologists blinded to specimen details reviewed each slide using light microscopy. The areas for light microscopic observation were selected from the most inflammatory or fibrotic portion. Cells were counted in each high-power field (HPF). Individual values were averaged to yield a histologic grade for each time point. The foreign body reaction was evaluated by foreign body giant cells, identified as fused macrophages generated in response to the presence of a large foreign body. Fibrosis was graded according to Common Toxicity Criteria with the measurement of fibrotic thickening [15].

\section{Statistical analysis}

The histologic characteristics were compared at each time period using the Kruskal-Wallis test. In 2-tailed tests, differences with P-values less than 0.05 were considered statistically significant. Results were analyzed with SAS 9.1 (SAS Institute Inc., Cary, NC, USA).

\section{RESULTS}

The implanted material was tolerated locally, with only slight neovascularization and no cell or tissue degeneration. All animals exhibited normal weight gain $(P<0.001)$ (Table 1) and displayed normal behavior without any symptoms of distress throughout the study. There was no recognizable inflammatory reaction, foreign body reaction, or fibrosis in the 30 control samples, which were dominated by fibers in the extracellular matrix and fibroblasts were suspended on light microscopic 
examination.

Experimental tissues were collected beginning from 30 days after implantation of NBCA and they revealed chronic inflammatory reactions (Fig. 1). Histological analysis showed that from days 30 to 360 , the number of lymphoplasma cells, neutrophils, and multinuclear giant cells decreased from 100 (range, 70-100) to 30 (range, 30-50), 2 (range, 2-30) to 0 (range, $0-2$ ), and 22 (range, 16-34) to 16 (range, 12-22) cells per HPF, respectively (Table 1 ).
After 30 days, microscopic observations revealed mild congestion and old hemorrhage with hemosiderin-laden macrophages. Histology showed slight diffuse infiltration of inflammatory cells, which significantly decreased over time (lymphoplasma cells, $\mathrm{P}=0.010$; neutrophils, $\mathrm{P}=0.017$ ). Hyaloid material was enclosed, reflecting foreign body reactions. The polymerization of NBCA was found to occlude the vasculature. Some portions of the vasculature were replaced by fibrosis. Endothelial regeneration was prominent.

Table 1. Tissue reaction according to time after n-butyl-2-cyanoacrylate implantation

\begin{tabular}{|c|c|c|c|c|c|}
\hline Characteristic & 30 Days & 90 Days & 180 Days & 360 Days & P-value \\
\hline No. of rats & 7 & 8 & 8 & 7 & \\
\hline Body weight (g) & $474(461-492)$ & $602(592-635)$ & $598(581-760)$ & $726(707-833)$ & $<0.001$ \\
\hline \multicolumn{6}{|c|}{ Inflammatory reaction $(\mathrm{n})$} \\
\hline Lymphoplasma cell & $100(70-100)$ & $53(50-85)$ & $30(24-100)$ & $30(30-50)$ & 0.010 \\
\hline Neutrophil & $2(2-30)$ & $0(0-1)$ & $0(0-2)$ & $0(0-2)$ & 0.017 \\
\hline \multicolumn{6}{|l|}{ Foreign body reaction } \\
\hline Giant cell (n) & $22(16-34)$ & $17(16-30)$ & $15(13-22)$ & $16(12-22)$ & 0.287 \\
\hline Fibrosis $(\mu \mathrm{m})$ & $338(276-514)$ & $307(217-510)$ & $291(217-482)$ & $266(210-415)$ & 0.600 \\
\hline Tissue necrosis & - & - & - & - & \\
\hline
\end{tabular}

Values are presented as median (range).

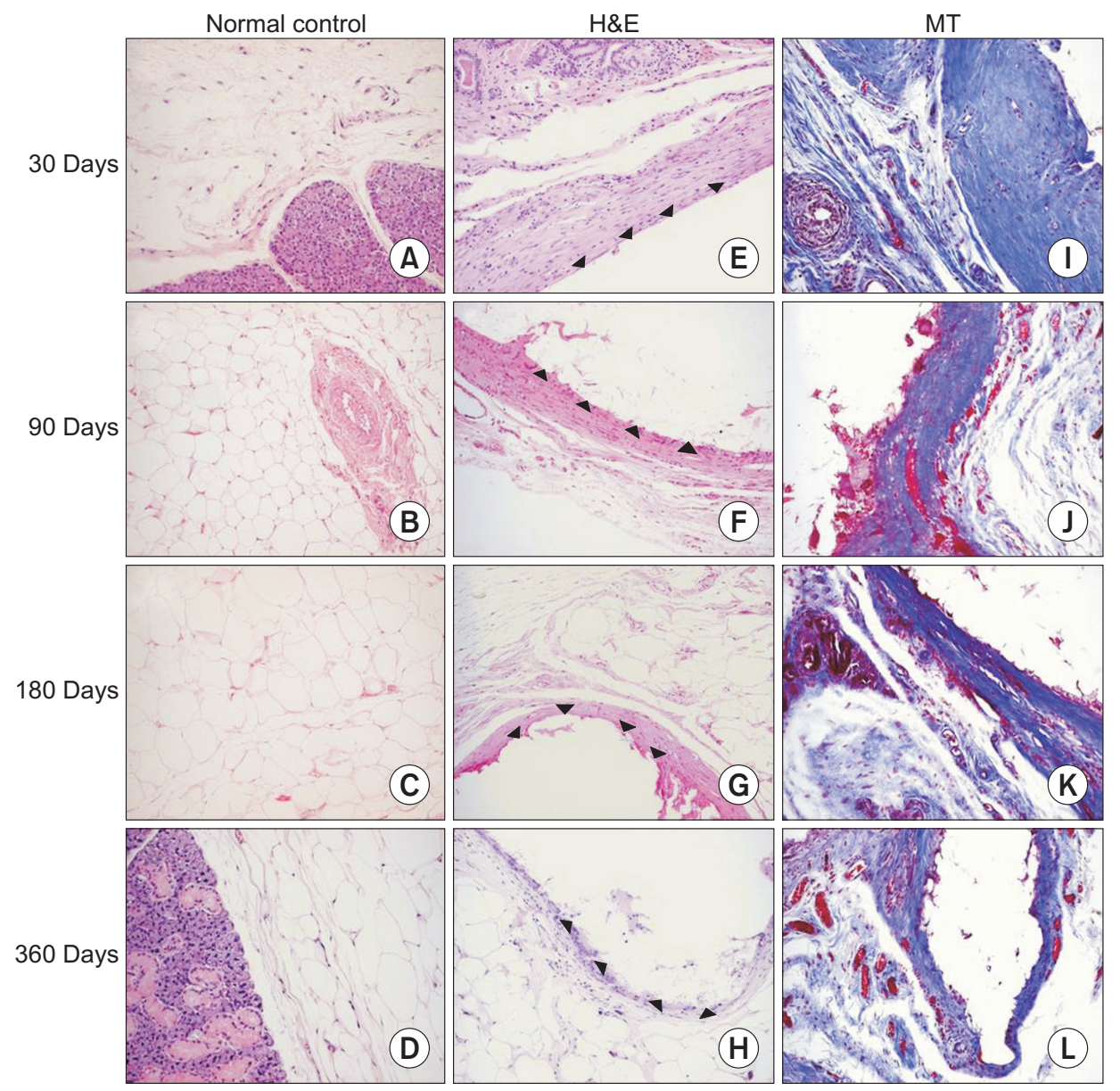

Fig. 1. Histology of experimental tissues was examined under a light microscope. (A-D) Normal control tissues were presented. $(\mathrm{E}-\mathrm{L})$ Black triangles indicated n-butyl-2-cyanoacrylate. (I-L) Connective tissue surrounding n-butyl-2-cyanoacrylate was stained blue. $\mathrm{H} \& \mathrm{E}$, hematoxylin and eosin; MT, Masson's trichrome (light microscopy, ×200). 
From 90-180 days, the glue appeared as hyaloid material without degeneration of cells or surrounding tissues. During this period, 13-30 multinuclear giant cells were observed per HPF, including the presences of a few macrophages. There was no significant difference in the number of multinuclear giant cells throughout the entire study period $(\mathrm{P}=0.287)$. The whole layers of the vasculature were completely regenerated.

After 360 days, histologic analysis revealed slight formation of noncellular fibrous connective tissue, slight infiltration of inflammatory cells, and focal accumulation of multinuclear giant cells (Fig. 2). The fibrosis measured $266 \mu \mathrm{m}$ (range, $210-415 \mu \mathrm{m})$. The skin could be slid and pinched up. The level of fibrosis was Common Toxicity Criteria ver. 4.0 grade 1 during the entire study period without further thickening $(P=0.600)$. However, maturation of fibrosis progressed gradually.

No signs of decomposition or resorption of NBCA were detectable. Cell or tissue necrosis or de novo neoplasia was not observed at any time point. There was no evidence of abscess formation.

\section{DISCUSSION}

The purpose behind investigating the biocompatibility of NBCA is to ensure its safety for cervical deep tissue application. In this study, we assessed the local histological effects of the implanted material in a living tissue. Inflammation significantly decreased, while the foreign body reaction remained stable over the 1-year observation period. The severity of fibrosis was Common Toxicity Criteria ver. 4.0 grade 1 during the entire study period; however, maturation of fibrosis progressed gradually. Precautions are needed with respect to preventing a sustained foreign body reaction and fibrosis although NBCA appeared to be a promising treatment for prevention of chyle leakage.

Chyle leakage is a potential complication of neck surgery that can result from lymphatic injury. The site of injury is commonly the terminus of the thoracic duct with the left subclavian vein [1]. Chyle leakage is accompanied by malnutrition and compromised immunity. Because a substantial amount of protein is transported in chyle, a sustained chyle leak can result in protein loss, leading to fluid shifts and increased metabolic
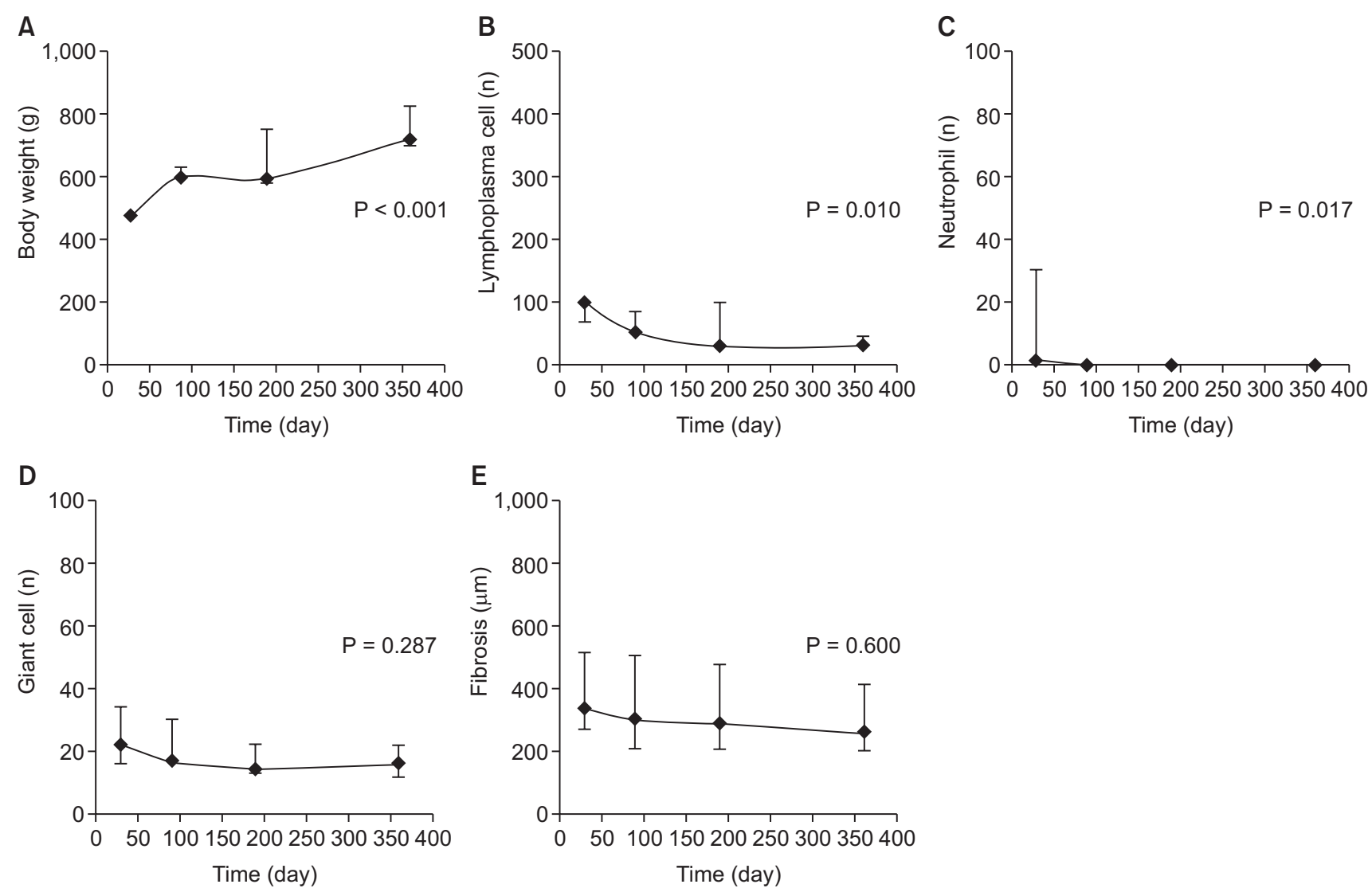

Fig. 2. Time series plots of tissue reaction show the local histologic effects of n-butyl-2-cyanoacrylate on a living tissue. Median values are connected by lines. Upper and lower whiskers represent their maximum and minimum values. (A) All animals exhibited normal weight gain. (B-D) Inflammation significantly decreased while the foreign body reaction remained stable over the 1-year observation period. (E) The level of fibrosis was Common Toxicity Criteria ver. 4.0 grade 1 during the entire study period without further thickening. 
demand. This complication can present significant treatment challenges.

Many physicians begin with conservative treatment, including adequate drainage, parenteral nutrition, and modified enteral feeding [3]. Modification of enteral nutrition involves a fat-free or low-fat diet supplemented with medium-chain triglyceride oil. A somatostatin analog could be used because it decreases the absorption of triglycerides [6]. A persistent leak necessitates neck exploration and ligation of the lymphatic(s), occasionally requiring muscle flap coverage. However, surgical intervention can considerably increase morbidity and mortality. Smoke and Delegge [1] reported that the postoperative mortality rate following ligation of the thoracic duct was $33 \%$, with an overall mortality of $14 \%$. It is difficult to reoperate in the same field, and it is not easy to identify and ligate the leaking lymphatic(s).

Recent reports have described the use of NBCA to stop chyle leakage with encouraging outcomes (Table 2). Muthusami et al. reported a case in which NBCA was successfully used to treat persistent chyle leakage following radical neck dissection [6]. In an effort to stop the lymphatic leak, $0.5 \mathrm{~mL}$ of NBCA was injected into the leakage point. In a case series, Blythe et al. [2] applied the maximum amount of NBCA, $1 \mathrm{~mL}$ per injection, to the damaged thoracic ducts during neck dissection. Patients in the study had no postoperative chyle leakage or other complications. However, these reports did not address the longterm safety or biocompatibility of NBCA.

Many studies have described the use of NBCA as a tissue adhesive. NBCA has been used with variable success rates for the treatment of bone fractures, ossicular fixation, embolization, fistulas, and hemostasis of esophageal varices or bleeding gastric ulcers as well as for vascular or tracheal anastomoses [7,13,16-25]. These remarkable studies attempted to show the potential applications of NBCA. However, the results achieved in these studies, did not provide evidence for the biocompatibility of NBCA in cervical deep tissues. Our current preclinical study demonstrated the detailed biocompatibility of NBCA in cervical deep tissue applications, reporting the potential risk of NBCA in the prevention of chyle leakage.

Cyanoacrylate adhesives are liquid monomers that polymerize quickly upon contact with tissue surfaces [12]. Polymerization of NBCA (Histoacryl, B. Braun; Glubran 2, GEM S.r.l., Viareggio,
Italy; Trufill, Cordis Neurovascular) begins with contact with hydroxide ions, which are dissolved in water, ambient air moisture, and body fluids [10]. During the exothermic reaction, ester monomers polymerize to form long cyanoacrylate polymer chains, resulting in a stable, water-resistant adhesive bond. Cyanoacrylate adhesives have various uses, and considerable research is underway to examine the application of certain cyanoacrylate products in a drug delivery system [12].

The possible problems associated with cyanoacrylate include local thermal damage and a low level of toxicity [26]. Attention should be paid to the generated heat because NBCA causes a highly exothermic polymerization reaction $[2,4,7,9,16]$. NBCA is not bioabsorbable; the body cannot break it down [12]. NBCA degrades slowly and forms few degradation products $[10,27]$. However, in the current study, we observed very little degradation of NBCA. NBCA should be applied cautiously to avoid placement in an unintended location. Improper placement may cause unnecessary adhesion, ulceration, local inflammation, and abscess formation. In our view, NBCA should be used only after carefully weighing the risks and benefits. NBCA users must decide individually whether NBCA is the appropriate material for the purpose, depending on the area of application.

To the best of our knowledge, this is the first preclinical study of NBCA application in the cervical deep tissues of an animal model to ensure the 1-year biocompatibility. Schneider and Otto [7] investigated the in vitro and in vivo effects of NBCA and analyzed the scientific literature. They reported that the effectiveness of NBCA as a soft-tissue adhesive depended on the surgical environment, purpose, amount used, and application technique. Optimized methods should be developed for each individual purpose. When using NBCA to prevent chylous fistulas in the neck, the visibility of the fistula is ascertained first. Surrounding structures are retracted so that they will not adhere to the NBCA. Blythe et al. [2] applied chloramphenicol $1 \%$ eye ointment to the carotid artery, the internal jugular vein, and the vagus nerve. Targeted application could be used to minimize the amount of NBCA required.

Our study had 3 limitations. First, a bias may have been induced in the unidirectional measurement of fibrosis based on paraffin sections, although efforts were made to include the thickest portion. Second, we focused only on the

Table 2. Summary of recent studies using n-butyl-2-cyanoacrylate to stop chyle leakage

\begin{tabular}{|c|c|c|c|c|}
\hline Study & No. & Design & Disease & Remarks \\
\hline Hwang et al. (2012) [8] & 1 & Case report & Reflux & Percutaneous embolization \\
\hline Blythe et al. (2011) [2] & 4 & Case series & - & - \\
\hline Schneider and Otto (2011) [7] & 6 & Preclinical study & - & Rabbit, 4-week observation \\
\hline Muthusami et al. (2005) [6] & 1 & Case report & Nasopharyngeal carcinoma & - \\
\hline Tuck et al. (2000) [5] & 1 & Case report & Clear cell carcinoma & Ureteral embolization \\
\hline
\end{tabular}


biocompatibility of NBCA in the cervical deep tissues of an animal model, and we only observed the reaction between NBCA and the surrounding tissue or organs. Treatment efficacy should be evaluated after an animal model of chyle leakage has been developed. Third, the amount of thermal injury was not investigated. The experimental research would be followed to analyze the severity of the generated heat. In addition, we assessed the histologic changes for only 1 year. A subsequent study should be performed to ascertain the long-term outcomes.

Our findings showed that NBCA was tolerated locally with only slight neovascularization and it did not cause cell or tissue degeneration in the cervical area of rats. Because of its biocompatibility profile and ability to polymerize in a moist environment, NBCA may be suitable for the treatment of chyle leakage. However, precautions are needed with respect to preventing a sustained foreign body reaction and fibrosis.

\section{CONFLICTS OF INTEREST}

No potential conflict of interest relevant to this article was reported.

\section{ACKNOWLEDGEMENTS}

This study was supported by the SNUBH Research Fund (grant number: 09-2014-007).

\section{REFERENCES}

1. Smoke A, Delegge MH. Chyle leaks: consensus on management? Nutr Clin Pract 2008;23:529-32.

2. Blythe JN, Habib A, Gulati A, Brennan PA. Use of N-butyl-2-cyanoacrylate tissue glue in thoracic duct injury during neck dissection surgery. Br J Oral Maxillofac Surg 2011;49:486-7.

3. de Gier HH, Balm AJ, Bruning PF, Gregor RT, Hilgers FJ. Systematic approach to the treatment of chylous leakage after neck dissection. Head Neck 1996;18:347-51.

4. Kukleta JF, Freytag C, Weber M. Efficiency and safety of mesh fixation in laparoscopic inguinal hernia repair using n-butyl cyanoacrylate: long-term biocompatibility in over 1,300 mesh fixations. Hernia 2012;16:153-62.

5. Tuck J, Pearce I, Pantelides M. Chyluria after radical nephrectomy treated with N-butyl-2-cyanoacrylate. J Urol 2000;164(3 Pt 1):778-9.

6. Muthusami JC, Raj JP, Gladwin D, Gaikwad P, Sylvester S. Persistent chyle leak following radical neck dissection: a solution that can be the solution. Ann R Coll Surg Engl 2005;87:379.

7. Schneider G, Otto $K$. In vitro and in vivo studies on the use of Histoacryl((®) as a soft tissue glue. Eur Arch Otorhinolaryngol 2012;269:1783-9.

8. Hwang PF, Ospina KA, Lee EH, Rehring
SR. Unconventional management of chyloascites after laparoscopic Nissen fundoplication. JSLS 2012;16:301-5.

9. Bozkurt MK, Saydam L. The use of cyanoacrylates for wound closure in head and neck surgery. Eur Arch Otorhinolaryngol 2008;265:331-5.

10. Quinn JV. Tissue adhesives in clinical medicine. 2nd ed. Hamilton (ON): BC Decker; 2005.

11. ASGE Technology Committee, Bhat YM, Banerjee S, Barth BA, Chauhan SS, Gottlieb KT, et al. Tissue adhesives: cyanoacrylate glue and fibrin sealant. Gastrointest Endosc 2013;78:209-15.

12. Mittal KL. Progress in adhesion and adhesives. Hoboken (NJ): John Wiley \& Sons; 2015.

13. Garcia-Tsao G, Bosch J. Management of varices and variceal hemorrhage in cirrhosis. N Engl J Med 2010;362:823-32.

14. Smith DG, Schenk MP. A dissection guide \& atlas to the rat. Englewood (CO): Morton Pub. Co.; 2001.

15. Common Terminology Criteria for Adverse Events v.4.0 (CTCAE) [Internet]. Bethesda (MD): U.S. Department of Health and Human Services, National Institutes of Health, National Cancer Institute; [cited 2016 Nov 8]. Available from: https://ctep. cancer.gov/protocolDevelopment/electronic_applications/ctc.htm.
16. Samuel PR, Roberts AC, Nigam A. The use of Indermil (n-butyl cyanoacrylate) in otorhinolaryngology and head and neck surgery. A preliminary report on the first 33 patients. J Laryngol Otol 1997;111:53640.

17. Kiyosue H, Mori H, Hori Y, Okahara M, Kawano K, Mizuki H. Treatment of mandibular arteriovenous malformation by transvenous embolization: a case report. Head Neck 1999;21:574-7.

18. Remonda L, Schroth G, Caversaccio M, Ladrach K, Lovblad KO, Zbaren P, et al. Endovascular treatment of acute and subacute hemorrhage in the head and neck. Arch Otolaryngol Head Neck Surg 2000;126:1255-62.

19. Suh DC, Kim KS, Lim SM, Shi HB, Choi CG, Lee HK, et al. Technical feasibility of embolizing aneurysms with glue (N-butyl 2-cyanoacrylate): experimental study in rabbits. AJNR Am J Neuroradiol 2003:24:1532-9.

20. Jayaraman MV, Do HM, Marks MP. Treatment of traumatic cervical arteriovenous fistulas with N-butyl-2-cyanoacrylate. AJNR Am J Neuroradiol 2007;28: 352-4.

21. Syal R, Tyagi I, Goyal A, Barai S, Parihar A. Multiple intraosseous hemangiomasinvestigation and role of N-butylcyanoacrylate in management. Head Neck 2007; 
29:512-7.

22. Camacho-Alonso F, Lopez-Jornet P. Clinical-pathological study of the healing of wounds provoked on the dorso-lingual mucosa in 186 albino rats. Otolaryngol Head Neck Surg 2007;136:119-24.

23. Tieu DD, Ghodke BV, Vo NJ, Perkins JA. Single-stage excision of localized head and neck venous malformations using preoperative glue embolization. Otolaryngol Head Neck Surg 2013;148:678-
84.

24. Bicer YO, Koybasi S, Kazaz H, Seyhan S. Effect of n-butyl-2-cyanoacrylate on the tensile strength and pressure resistance of tracheal anastomoses ex vivo. Otolaryngol Head Neck Surg 2015;152:297-301.

25. de Sena LA, de Almeida MS, de Oliveira Fernandes GV, Guerra Bretana RM, CastroSilva II, Granjeiro JM, et al. Biocompatibility of wollastonite-poly(N-butyl-2-cyanoacrylate) composites. J Biomed Mater
Res B Appl Biomater 2014;102:1121-9.

26. Toriumi DM, Raslan WF, Friedman M, Tardy ME. Histotoxicity of cyanoacrylate tissue adhesives. A comparative study. Arch Otolaryngol Head Neck Surg 1990; 116:546-50.

27. Ciapetti G, Stea S, Cenni E, Sudanese A, Marraro D, Toni A, et al. Toxicity of cyanoacrylates in vitro using extract dilution assay on cell cultures. Biomaterials 1994; 15:92-6. 